\title{
Research on the Current Situation of Martial Art Teaching in Confucius Institute and Its Countermeasures
}

\author{
Hongyu Liu \\ ChangZhou Campus \\ Hohai University \\ Changzhou, Jiangsu, China 213022
}

\begin{abstract}
As an important platform to spread Chinese culture to overseas and promote international exchanges and cooperation, the promotion of martial arts in Confucius Institute is an important means also an effective way to output traditional Chinese culture as well as internationalize martial arts. This paper mainly analyzes the constraints to carry out martial art classes and promote martial arts, proposes advice and countermeasures on the launch of martial art teaching in Confucius Institute and promotion of martial arts, and aims to provide valuable references for the development and promotion of the internationalization of Chinese martial arts by domestic Confucius Institutes. Meanwhile, it allows the world to better understand Chinese culture and better learn Chinese martial arts.
\end{abstract}

Keywords-confucius institute; martial art teaching; present situation; countermeasures

\section{INTRODUCTION}

In the era of cultural integration, Chinese culture is reaching out to the world, and the effective dialogue between eastern and western cultures is an irreversible trend. However, simple verbal communication is too dull, therefore Chinese martial art international promotion strategy hopes to let the world people to learn Chinese and understand Chinese culture by practicing martial art and through international promotion of martial art, thus developing Chinese culture to be a charming part in the world cultural spirit, and gaining more world-wide reputation for the Chinese nation. Due to geographical location, our external promotion of martial art at this stage still stays in Asian regions, hence we should proceed from the overall development and outreach the promoting scope to global world especially Europe (which is another major area for the implementation of Chinese martial art international strategy) taking Confucius Institute as a carrier. Most of the world's major developed countries are located in Europe, by taking Europe as one of the regions for key promotion of martial art international promotion strategy, on the one hand it will resist Western cultural hegemony and protect native traditional culture by international promotion of martial art, on the other hand it aims to disseminate "harmony" culture to the West that has different cultures with us through the implementation of martial art international promotion strategy and learning exchanges of martial art, thus eliminating suspicions of West due to different social systems, achieving peaceful co-existence and co-building a harmonious world.

\section{GlobAl PROMOTION OF CONFUCIUS INSTITUTE AND MARTIAL ART}

Ever since the first Confucius Institute was listed in Seoul, South Korean capital in 2004, up to September 2014, China Hanban has established 457 Confucius Institutes and 707 Confucius Classrooms by cooperation with 122 global countries, also become a global brand and platform for promoting Chinese language teaching and dissemination of Chinese culture. One of the most important works for Confucius Institute is to provide standard and authoritative modern Chinese language teaching materials for Chinese learners around the world as well as to offer the most regular and leading Chinese teaching channels. Currently, there are more than 640 universities in the United States have began offering specialized Chinese learning programs, and more than 50,000 high school students are learning Chinese in Thailand. In Thailand, the number of schools at all levels that open Chinese courses is increased from 242 in 2003 to 1105 , the number of students learning Chinese is increased from 50,000 to 400,000 . Besides, Malaysian government listed the target of cultivating 10,000 Malaysian Chinese elites by 2008 into the national "Ninth Five-Year plan". Confucius Institute carries the mission for the world to promote Chinese language, spread Chinese culture, enhance understanding of China, develop friendly relations between China and foreign countries, facilitate development of the world's multi-culture, and contribute to building a harmonious world. The global layout of Confucius Institutes has taken an initial shape, through an in-depth understanding of national conditions of local area, including customs, manners, religion and other traditional culture, a series of academic and non-academic Chinese courses from kindergarten to university have been launched; and a variety of activities have been carried out, which basically meet the requirements of local people, and achieved preliminary results.

After years of effort and practice, the internationalization process of Chinese martial art has taken a major step, also 
made considerable achievements. However, compared with the world's developed countries' publicity strategies and dissemination means of their national traditional forms of physical training with advantages, our external promotion of martial art still exists some gaps. First, Chinese foreign teaching of martial art lacks unified management and standard. In the current American society, various popular martial arts in the world have their own markets, and there are more than 3,000 martial art clubs. As far as Asia is concerned, there are South Korean taekwondo, Japanese judo, karate, kendo, Vietnamese boxing, Thai boxing, Philippine truncheons, etc. Wherein, the influence of South Korean taekwondo and Japanese karate is the largest, with most rigorous organization, and they attracted a large number of enthusiasts with standardized textbooks, uniform clothing and appraisal system of Dan-system, etc. In contrast, Chinese martial art lacks unified management, various martial art institutions and schools lack mutual communication and cooperation and each leads their own way; teaching contents are varied, which lack unified contents and evaluation criteria; many martial art teachers emphasizes teaching techniques to students, and neglect system theory and cultural edification, thus students' cultural atmosphere in learning martial art is inferior to learning taekwondo, karate or judo. As a typical representative of traditional Chinese culture, martial art has received warm welcome by Confucius Institutes around the world. Currently, there is one out of every three Confucius Institutes has opened martial art classroom, with Taiji, long boxing, kung fu fan as the main teaching contents of martial art classroom. Henan Songshan Shaolin Martial Art Vocational Institute is one of the first batch of schools for international promotion of Chinese, which provides Hanban with martial art curriculum teaching, martial art teacher training, global martial art tour and "Chinese and martial art" multimedia series textbooks researching and developing as well as other aspects of personnel and facilities. Today, Hanban has dispatched nearly 5,000 Chinese teachers and volunteers with a certain basis of martial art to 48 countries around the world to teach martial art courses in Confucius Institutes: data shows that currently nearly two-thirds of martial art education teachers in Confucius Institute come from volunteers and government sponsored Chinese teachers. The overseas dissemination composite Hanban/ Confucius Institute Headquarters of Confucius Institute martial art take cultural exchange and cultural internationalization as purposes. Martial art contains the quintessence of our traditional culture, and particularly the martial virtue profoundly embodies the thoughts and spirit of benevolence, righteousness, propriety, wisdom, faith, etc. in confucianism, which conform to the cultural dissemination standards to the world.

\section{CONSTRAintS IN MARTIAL ART PROMOTION BY CONFUCIUS INSTITUTE}

It is undeniable that, Confucius Institute has played a certain role in the promotion and popularization of Chinese martial art, however in terms of the long term development of Chinese martial art, the teaching of martial art classes by volunteers and government sponsored teachers will greatly affect audiences' in-depth understanding of the cultural connotation of Chinese martial art and improvement of technical levels, and even misleading the cultural essence of Chinese martial art. Moreover, there are also deficiencies in initiatives for the promotion of Chinese martial art. Through survey in professional bookstores in France, Holland, Italy, Germany, etc., Long Guoqiang (2007) found foreign language version of martial art textbooks, CDs , newspapers are scarce. The culture propaganda of Chinese martial art is extremely lacking in Europe, and the propaganda efforts of Chinese martial art on television and newspapers also fall short to Japanese judo and karate, various competitions on European television media never televised or broadcasted Chinese martial art, the reason is that the number of participants and audiences of Chinese martial art is still far from the extent of television media attention. The number of participants of karate, judo, taekwondo competitions held in Europe is about 2000-3000, the there are huge crowds of audiences, while there are up to just 200-300 people in a martial art match. Thirdly, lack of professional martial art teachers and insufficient intervention of government agencies. In 2007, the martial art delegation sent by Wushu Administrative Center of General Administration of Sport only had 80 people, with 35 teachers teaching abroad.

\section{A. Martial Art Forms Promoted by Confucius Institute}

Martial art of Confucius Institute in various countries are mainly spread by four forms: (1) offer special martial art classes; (2) hold martial art lectures; (3) conduct martial art performance; (4) launch martial art learning activities in summer camp. What is called, loss of a thousand miles, if the least bit bad. Precision of teaching level cannot be realized as well as true communication and promotion of Chinese martial art cannot be reached without professional and highlevel teachers. However, most Confucius Institutes are especially seriously short of martial art teaching during promotion of martial art. Along with more and more urgent demand for offering martial art classes by Confucius Institutes in various countries, currently Confucius Institute Headquarters has not formulated unified martial art classes plan and outline and even has no unified requirements and standards, while the dispatched teachers are not professional martial art teachers. True martial art practice shall be based on long-term physical exercise and hard training, decrease of teaching level may affect quality of martial art spreading due to limitation of level of martial art spreaders, meanwhile, it will greatly affect promotion process of martial art to the world.

\section{B. Teaching Materials Management and Teaching Contents Cannot Reach Fixed Unity}

Chinese martial art is extensive and profound, and goes back from ancient times. According to incomplete statistics of data, now sources spreading everywhere are orderly, the boxing theory is clear and the style is unique. There are more than 129 boxing schools with their own systems. Each boxing style is unique and has different attack and defense technological means. Therefore, we cannot promote all the boxing schools to the world and it is impossible. Teaching materials taught in different martial art clubs and organizations are different, and there are no fixed teaching 
contents. It is difficult to realize orderly management in management; even some organizations do not pass approval but cheat and bluff other in the disguise of publicizing martial art culture and put image of the nation aside.

\section{Shortage of Comprehensive Teacher Ability}

Martial art teachers teaching in foreign countries are very deficient in our country. Many teachers with good martial art skills are unable to keep pace with foreign language communication skills; conversely, teachers with high foreign language skills have poor martial art skills, which greatly hinder development of martial art. Martial art teaching cannot be conducted smoothly without professional and qualified martial art teachers. Language is a large obstacle for internal promotion strategy of martial art. Without relying on language, the learner cannot rightly appreciate many martial art essentials at all.

\section{Attention and Publicity Given by the Government Is Not Enough}

At present, publicity for martial art by the government only stays the slogan of entering Olympic Games. After Chinese martial art succeeds in bid for Olympics, vigorous publicity for martial art, especially international publicity and promotion for martial art is particularly urgent and important. However, through a general survey, it is likely that our country and internal martial art do not pay more attention to it, they do not put it into practice and not practically consider actual conditions of Chinese martial art.

\section{SUGGESTIONS AND COUNTERMEASURES FOR IMPLEMENTATION OF MARTIAL ART TEACHING AND PROMOTION BY CONFUCIUS INSTITUTE}

\section{A. Change Communication Concept and Promote Interdisciplinary Communication}

"Hoe one's own potatoes" is the portrayal of Confucius Institute spreading Chinese and martial art currently, which is also a large drawback. Confucius Institute is still at primary stage of teaching Chinese and Tai Chi Chuan in communication contents, only "martial art" is not extended to "doctrine". Both Chinese and martial art belong to an important part of Chinese traditional culture, they shall draw on the strong points of others to make up for one's own weak points during communication process. Martial art is a sports program to explain connotation of Chinese traditional culture by body actions. For example, during communication process, Chinese traditional culture and body actions are blended with each other and they rely on each other, which will be more beneficial for development of discipline and speed up communication and development of martial art and Chinese in Confucius Institute.

\section{B. Offer Various Forms of Martial Art Martial Art Classes and Build up Martial Art Image in Confucius Institute}

Since Confucius Institute is established, a tide of "Chinese craze" has been raised all over the world. As founder of Confucianism, Confucius Institute possesses the core of "benevolence", "righteousness" and "harmoniousness", which is idealism and harmonious friend today. This Confucian thought does not only deeply influence Chinese, but also influences foreign countries and even the world. Prominence of Confucius Institutes around the world reveals influence of Confucianism. Martial art enters Confucius Institute classes, which makes students excellent in both literacy and martial arts and bring out the best in each other. We cannot only open up practical classes, but also give video lessons, allow students to watch a number of representative action films, different forms of martial art performance and lectures, etc. Meanwhile, we praise highly some representative martial art giant stars, such as Jet Li, Jackie Chan and so on. We should strengthen publicity strength of network media. We can also invite some masters and Kung fu giant stars to set up lectures in Confucius Institutes around the world.

\section{Edit Characteristic Teaching Materials}

Confucius Institute has already provided powerful conditions for international communication and development for martial art; next the first thing we have to do is compile a set of suitable martial art materials. This is a great project and plays a decisive role during communication process and due attention should be paid to it. During materials compilation, we should seek common ground while maintaining difference, notice that materials should have unified standards but the principle of adjusting measures to local conditions should be followed. Confucius Institutes all over the world should be allowed to start from their student source conditions and make adjustment on the premise of unified standards. They should teach students in accordance with their aptitude, implement easy learning and easy exercise, truly achieve the training inside and outside and open up characteristic and dynamic martial art classes.

\section{Strengthen Teacher Strength of Confucius Institute}

The teachers welled-educated and trained in military exercises are the first choice of course teachers in Confucius Institute. Martial art and Chinese are complementary and blended, and both lessons are given to students, which cannot only improve teaching effect, but also is a challenge for course teachers. Therefore, we should strengthen the efforts to cultivate teachers and strictly guard a pass. The teachers teaching Chinese shall possess certain ability of giving martial art lessons as well as understand certain basic knowledge of martial art cultural background, which cannot only solve teachers shortage problem but also has due effect in publicizing martial art.

\section{E. Increase Training Bases of Confucius Institute and Set up Corresponding Courses}

Preparation for cultivating excellent teachers for long term shall be made well. Special training bases can be established and corresponding departments can be established in colleges and universities. From admission, interests of highly educated talents shall be cultivated; course should be increased according to highly educated talents' hobbies and interests, and theoretical and practical ability of 
teachers who give lessons in Confucius Institute all over the world should be systematically cultivated. On one hand, teachers management talents are taken as direction; on the other hand, some comprehensive multifunction talents who mainly give actual combat performance and open lecture should be cultivated. Professional systematic course training program of specialty should be applied and should be allowed to enter campus and become an independent major.

\section{CONCLUSION}

Martial art classes teaching launched in Confucius Institute plays an important role in internationalization promotion of martial art; also as every colleague's current and long-term goal in martial art field, internationalization of martial art is necessity of historical development as indispensable mission of Chinese ethnic peoples. We should relay on the platform of Confucius Institute, seize development chance, on the large background of allowed by policy, join forces with all sectors of society and carry forward martial art in Confucius Institute and make martial art become a bright pearl of future sports team and make more and more people participate in and enjoy it.

\section{REFERENCES}

[1] Hanban/Confucius Institute Headquarters. About Confucius Institute/Classroom [EB/OL].[2014-06-

10].http://www.hanban.edu.cn/confuciousinstitutes/node_10961.htm

[2] YU Dinghai. A Study on the Promotion Mode of Martial art in the Confucius Institute[J]. Journal of Shanghai University of Sport, 2011(1).

[3] National Sports General Administration of Sports Management Center. Five-Year Plan of Chinese Martial art Development (20102014) [R]. 2010:3.

[4] LIU Yandong points out at the opening ceremony of Confucius Institute Conference: promote business development of Confucius Institute together and compose new chapter of cultural and educational exchanges between China and foreign countries. [N]. People's Daily, 2013-12-8 (004). 